\title{
Gálvez y su laberinto
}

Sólo me interesa el aspecto psicológico de la cuestión. Y también el colectivo en cuanto contiene en su esencia la transformación espiritual de mi país.

He querido encerrar en este libro un momento de la transformación espiritual de nuestro país. ${ }^{1}$

$\mathrm{A}^{\mathrm{N}}$ esto es en lo que insiste y vuelve a insistir Gálvez: él quiere describir la vida argentina. ${ }^{2}$ Entendiendo por vida, claro está, los procesos espirituales propios a los habitantes de su país. ${ }^{3}$ Etapa por etapa, comenzando por la provincia, ha ido recorriendo lo que es, según él, la vida argentina. Analizándola. Tratando de captar lo esencial, lo característico, lo propio de ella. Refiriendo su formación, material y espiritual. Amando a su Argentina como tantos argentinos ilustres (amor que no sé si existe en mayor grado entre los escritores argentinos que entre los de los otros países sudamericanos, pero que sí sé que se manifiesta en aquéllos mucho más a menudo), Gálvez trata de comprenderla y analizarla objetivamente. Es completamente sincero al intentarlo: lo dice una y otra vez, en sus prólogos ${ }^{4}$ - La tragedia de un hombre fuerte, Nacha Régules, La ciudad pintada de rojo- y parece convencido de haberlo conseguido. Pero ¿lo ha conseguido ${ }^{5}{ }^{5}$ ¿No es que, al tratar de retratar a un pueblo, se ha retratado a sí mismo? Porque ¿son las cosas, las personas, el mundo exterior tal como lo vemos? \& Es mi realidad circundante la misma que la de mi vecino? ¿Ven ellos, ellas, los otros, a las gentes tales como yo las veo? Estas preguntas se me han venido a la mente un sinnúmero de veces al leer a Gálvez. Precisamente porque él está tan seguro de su objetividad. 
¿No podría ser que Gálvez, al querer retratar el crecimiento y desarrollo del alma de un pueblo, retratara su propia alma ? ${ }^{6} \mathrm{Y}$ sin hacerlo tan personal, ¿cuánta influencia tiene una escuela de pensamiento, tienen ciertas teorías y fórmulas, sobre la realidad independiente de ellas, si es que ésta existe? ${ }^{7}$

¿Al insistir tanto en que sus caracteres son independientes y en que las ideas que expresa en sus libros no son las suyas propias?, ¿no se equivoca Gálvez al creerse capaz de tanta objetividad? ¿Se pueden creer a un escritor estas afirmaciones, por más rotundamente que las presente, si a través de sus libros se ve el desarrollo del mismo hombre como personaje: enriquecido por sus experiencias, afinándose, reafirmándose, pero siempre el mismo hombre?

Hay otra característica de la Argentina que Gálvez trata de demostrar a través de sus distintos caracteres femeninos: la del espíritu estático de la vida provinciana, en contraposición al espíritu dinámico de la vida porteña. Pero ¿̇aprueba o desaprueba completamente o, para definirlo más claramente, encuentra más potencialidades, más savia, más glóbulos rojos en las provincias o en la metrópoli? Su posición no es clara, como la de Mallea. A través de su obra, combatiendo al espíritu estático y criticando los resultados del espíritu dinámico, su mente duda entre las ventajas y los males del espíritu dinámico al cual ađmira, y las reservas de energía, unidas al tradicionalismo, el conservadorismo y las pequeñeces de espíritu que sabe propias de las provincias.

Podríamos añadir algunas preguntas a nuestra ya vasta colección, pues para sentir, definir y explicar a un país se necesitan especiales cualidades que no todos poseemos. Si se pudiera medir eso en alguna forma, nos preguntaríamos ¿ cuán argentino es Gálvez? Después de todo casi se podría jurar que su educación ha estado completamente regida por normas europeas, que lo que más ha leído (hasta el tiempo en que publicó las novelas de que nos vamos a ocupar) son obras francesas y rusas. Basta leer sus obras, escuchar a sus críticos y saber que él mismo nunca to ha desmentido. Es suficiente citar a un crítico. ${ }^{8} \mathrm{El}$ mismo, a través de sus personajes, habla de sus lecturas. Etc., etc. El hecho existe. Lo que importa es saber cuánta influencia tienen nuestro amor y admiración por otros pueblos y por su obra, en el afecto que sentimos por el nuestro. $Y$ aunque no influya en nuestro afecto, una educación cosmopolita con 
especial insistencia en lo francés, ¿ influye o no en un autor en cuanto a comprender a su país se refiere? Cito a tres autores ${ }^{8}$ pero en este caso concreto, por falta de pruebas sobre las que se apoyen teorías no muy seguras, queda la interrogación sin respuesta.

Antes de terminar esta enumeración de dudas, interrogaciones y consideraciones, que se va alargando más de lo que la prudencia aconseja, es necesario anotar una más, que tiene bastante importancia en el tema en cuestión y que es la de no saber hasta qué punto puede un hombre, por inteligente que sea, por comprensivo, por objetivo que sea, adentrarse en la mente y el corazón femeninos, o viceversa. Hasta qué punto es esto hacedero y cómo saberlo, parece ser asunto problemático en extremo. Pero sin tener el hilo de Ariadna ni medios para encontrarlo, se hace necesario entrar en el laberinto.

\section{RASELDA}

"La quietud provinciana of rece más motivos poéticos de desarrollo", dice Julio Noé ${ }^{10}$ acerca del tema principal de esta novela - La maestra normal-, y así parece ser, pues se debe contar entre las obras más poéticas de Gálvez. Y una de las más reales, al mismo tiempo (es lógico, después de todo, que realismo y emoción vayan unidos). ${ }^{11}$

Gálvez publica este libro cuando tiene treinta y dos años. En él está toda su experiencia de la vida provinciana. Raselda representa su espíritu, el espíritu estático provinciano, y la descripción que Gálvez hace de ella es la descripción que lleva dentro de sí mismo.

Las pinturas son excelentes. A este respecto, Cejador la llena de alabanzas (en esa forma tan característicamente suya). ${ }^{12}$

Dulce, romántica, soñadora (soñadora de amor) de poca voluntad, de carácter suave y tímido y sumiso. Encontrando siempre la realidad inferior a sus ensueños. Su falta de energía, vitalidad e interés en otra cosa que no sea sus pequeñitos problemas sentimentales, la imposibilita para tener éxito en sus labores de maestra. Hasta que la tragedia irrumpe sobre esa alma débil y suave, hace pedazos el mundo en que vivía, pero no la cambia. Raselda sigue sumisa y 
resignada, acepta su suerte, el destino la lleva. Es el alma estática de la provincia, incapaz de cambio, aceptando su destino, pero fuerte en sus resignaciones, sumisa en los sufrimientos.

Y la impresión que produce en el lector es muy semejante. Provoca a compasión y lástima esa figura tan femenina y tan indefensa. iHubiera podido ser una tan típica y tan excelente ama de casa provinciana! Pero eso es todo. No despierta interés. Podemos comprender a Solis, el infame (e inocente) seductor, al hombre de alma inquieta que la abandona. iDespierta tan poco interés, aparte del meramente sensual! Todo su encanto estriba en esa atmósfera femeninamente poética que la rodea. Como a las provincianas.

La historia, que narrada en pocas frases resulta brutal y común en extremo, pero que forma un bello libro, es la siguiente: Raselda es nombrada maestra en la Escuela Normal de Maestras. Sobrevienen las intrigas típicamente provincianas, agravadas por su ineptitud y el pasado escabroso de su madre. Llega Solís de Buenos Aires, la enamora casi por no tener otra cosa que hacer; se marcha a Buenos Aires abandonándola; ella descubre que va a tener un hijo, y se somete a una operación que descubierta propaga su desventura por La Rioja. Habiendo fracasado en su trabajo y en amores, es enviada a un puesto muy inferior, en un lugar mucho más pequeño, del que, debido a las acostumbradas malas lenguas pueblerinas, es trasladada finalmente a un miserable lugar cerca de la frontera andina, donde se dedica a practicar la rreligión.

$\mathrm{Y}$ toda esta tragedia sucede sin que ella haya tenido casi parte en ella. ¿Qué ha hecho ella para verse expuesta a tanta miseria? Solamente soñar. Eso es todo. Es un juguete de las circunstancias y no tiene la culpa de no saber vivir. ¿Y dónde lo iba a aprender? $¿$ En la provincia? ¿En ese ambiente de quietud, sueño y vacío infinitos, de calma desesperante, tan bien pintado por Gálvez? ( $Y$ es necesario haber vivido años enteros en una ciudad sudamericana de ese tamaño, para comprender el sentido de sus palabras, para poder, al leer la novela, empaparse de la sensación de quietismo infinito de un verano en provincias).

¡Pobre Raselda! ¡Víctima inocente del espíritu estático de las provincias! ¡Pobre Raselda! Que no despierta ningún sentimiento grande. ¡Ni siquiera una gran compasión! 


\section{NACHA}

Un carácter mucho más complicado es el de Nacha Régules, la triste heroína del libro del mismo nombre. Libro que está formado por la sucesión de descripciones de las miserias a que está sujeta una mujer joven y pobre, en Buenos Aires. Descripciones de miserias, de tristezas, de brutalidades es este libro, que es el que más se encuentra influenciado por el naturalismo y los grandes escritores rusos. Mario Rodrigues dice que Nacha no es sino una hermana de Sonia $;^{8}$ pero, yo diría, sin la hondura psicológica de ésta, sin que Gálvez pueda alcanzar ni de lejos la maestría del magnífico Dostoiewsky, cuando nos deja entrever esa alma de mujer; sin la belleza de la explicación del porqué del martirio de Sonia, sin la altura de su renunciación.

Eso es lo difícil de entender en el libro de Gálvez. La razón de las acciones de mutchos personajes. Uno puede sentir que el autor mismo se encuentra a menudo con el difícil problema de tener que explicar a Nacha y de hallarse incapacitado para hacerlo. $Y$ entonces hace hablar a su personaje, ${ }^{13}$ que se pregunta a sí misma el porqué de sus propias acciones. Eso no es absolutamente difícil de comprender: a todos nos sucede alguna vez hacer algo que después no podemos explicarnos. Pero to que resulta poco convincente es esa su constante repetición: ; Era mi destino!, ${ }^{14}$ sin que tenga una completa conciencia de ello. En algunas ocasiones estuvo en sus manos el cambiar su destino y no lo hizo (como, por ejemplo, cuando Monsalvat le ruega casarse con él), y para explicar esto, Gálvez empieza a dar a éste, caracteres psicológicos de una hondura completamente inesperada y poco de acuerdo con las circunstancias que acaba de describir y al carácter de Nacha que sugiere en las primeras páginas $\mathrm{y}$ en sus otros libros (El mal metafísico, La maestra normal). Hay algo de demasiado trágico, de demasiado sublime (precisamente porque la Academia no nos deja usar la palabra en este sentido) que da a la novela un ambiente extranjero, un ambiente tolstoiano, que desafina, en contacto con la poca espiritualidad de Nacha, por más esfuerzos que haga Gálvez para convencernos de lo contrario. 
Cuán diferente es la actitud de Sonia, tan sencillamente resignada a su destino, sin una sola vez mencionarlo. Resignación que se nos transmite serenamente, sin ademanes trágicos. $\mathrm{Y}$ aquí estamos en desacuerdo con Stefan Zweig que escribió a Gálvez: "Su novela es de un realismo ptnzante sin sentimentalidad y llena de sentimiento ..." 15

Otro defecto que encontramos en la descripción de esta alma femenina es su repetición, el acumular escenas semejantes en que mujeres parecidas que han soportado idénticas desventuras, relatan las mismas tristezas con las mismas palabras. Al querer reforzar sus palabras, Gálvez les ha disminuído su fuerza. "Describir átbol por árbol es el peor de los caminos para describir un bosque", ha dicho cierto crítico refiriéndose a Jornadas de agonía de Gálvez ${ }^{16}$ y encuentro que la misma observación se puede repetir aquí.

$Y$ aunque es difícil generalizar y quizás esta afirmación no sea tan general o exacta como debiera ser, se podría decir que en esta novela no se llega al espíritu de Nacha por exceso de documentación, y no por falta de ella, y que en esta obra el autor da más importancia a los sucesos que relata o a la impresión que quiere producir, que al estudio psicológico de esta mujer, su principal personaje. Por el contrario, recordamos a A. Chapman, cuando dice refiriéndose a una novela de Amunátegui Jordán “... esta novela ofrece un pensamiento: que la ciudad, proyectada hasta el interior del microcosmos, guarda eterna indiferencia por las ambiciones de los individuos..." 17 aunque en Gálvez este pensamiento está mucho menos claro, es mucho menos fuerte, mucho más diluído.

\section{LITA}

Otra indeterminada figura femenina es la de Lita. Lita, desdibujada, perdida, aplastada por la personalidad de Carlos Riga, y gue, a pesar de constituir algo así como una triste y suave melodía recurrente, en esta sinfonía de angustia y de fracaso que es $E l$ mal metafísico, nunca acaba de definirse. Es que las mujeres de Gálvez, más aún que los hombres, son criaturas esclavas de las circunstancias, del medio ambiente, de la atmósfera de la provincia o de la 
ciudad. : No lo vemos así en Raselda, Nacha Régules, Quica (la de Una mujer muy moderna) Lita, su quinteto de La tragedia de un hombre fuerte y las otras?

Pero unas pocas páginas bastan para hacer a Lita inolvidable. ¡Es tan real, tan sentida la descripción de esta "estatuita de Tanagra", que genuinamente asqueada por la frivolidad de su vida, sigue viviendo su vida frívola! ${ }^{18}$

iQué hastío el de la vida de una mujer inteligente y refinada, en la sociedad de Buenos Aires por aquellos años! (el libro lleva la fecha 1922). ¿Qué rebeldía la que se siente contra toda esa tontería humana encarnada en su madre, sus amigas, y "los mocitos" elegantes que la rodean; rebeldia muy grande, pero nunca lo suficientemente grande como para hacerla romper con esa sociedad y dejarla!

Es ésta quizás una de las figuras más sinceras de Gálvez, y esta impresión de verosimilitud que produce se debe a varias razones: 1) a que no hace nunca nada, y porque no le pasa nada -a este respecto sería interesante hacer un estudio comparativo en literatura, y quizás mostrar cuánto más grande es la atmósfera de realidad que rodea a los personajes a quienes no les sucede nada ( ¿ perogrullada?) - ; 2) por el carácter algo vago de su dibujo, por lo contradictorio en ella, por ese su anhelar tanto algo que no sabe 1o que es; 3 ) por la perfección de su retrato físico. Porque esa es una de las grandes cualidades del Gálvez novelista: el poder pintar a una persona, un cuadro, una emoción, una experiencia, en cuatro frases. Dondequiera que Lita aparece, está frente a nosotros pintada en una frase, sentida en un movimiento: "figurita de Tanagra" con "súbitas expresiones de pilluelo" y modo de hablar "brusco". Pobre desencantada de Loti, vida estéril y frívola que tuvo en sí tantas potencialidades.

Gálvez conoció bien el tipo, pues no es éste el único ejemplo de esta clase de figura. La tenemos en sus cuentos, en personajes secundarios, y aparece a menuđo, siempre la misma. Fué la figura de mujer de alta clase social, típica del Buenos Aires de ese tiempo. Tipo de "gamine" que apareció en todo el mundo occidental.

Fué fácil describir esa vida y esas conversaciones; difícil culpar a una mujer tan encantadora y con rasgos tan originales por no tener aún más originalidad, más energía para vivir. $\mathrm{Y}$ además, es 
en sus debilidades, en sus defectos, donde podemos notar la buena pintura de carácter de mujer, el acierto de Gálvez en su pintura de esta alma femenina.

¿Lo que ella hace? Nada. Quejarse de la frivolidad de su existencia, leer un poco y dejarse amar por Carlos Riga, el poeta maldito, tan bien descrito por Gálvez, siendo la causa sin quererlo, y casi sin saberlo, del fracaso de su vida. Eso es todo.

Al leer la descripción que de ella hace el novelista, no es difícil comprender que una personita así produjera en Carlos Riga, sentimental incorregible, la pasión que fué una de las causas de su miserable vida. $\mathrm{Y}$ es tan fácil entender que ella nunca pudiera estar a la altura de ese amor. ¡Pobre Lita! ¡ Lo reales que son las triviales tristezas y fracasos de su vida!

\section{ASUNCION}

O el amor estático. $Y$ otra vez volvemos a las diferencias entre provincia y ciudad. Porque como dice Salaverri ${ }^{19}$ al referirse a La tragedia de un hombre fuerte, "Toda la cuestión estaba alli, en ese conflicto entre la vida colonial y la vida moderna, entre el espiritu estático y el espíritu dinámico". Un caso diferente al de Raselda, aun cuando el personaje central sea el mismo. En el caso de Kaselda se trata de la provinciana en su provincia, el ejemplo de la formación que da ese ambiente, el prototipo de joven muchacha pueblerina. En Asunción se produce el choque entre los dos ambientes, se muestra el resultado de la educación del pueblo, en el ejemplo de mujer casada ya formada, que ha desarrollado todas sus posibilidades.

Y al espíritu estático se le culpa de un modo absoluto, por el fracaso de ese matrimonio. Como provinciana muy católica y como muy católica poco comprensiva, Asunción es exactamente lo opuesto de lo que la energía de su esposo y su amor a la vida, necesitan. $\mathrm{He}$ aquí unas cuantas frases de Gálvez, al respecto: "Asunción, como todas las provincianas, no era coqueta". "Como todas las mujeres argentinas había sido engañada respecto a la vida, a los hombres y al amor. Engañada por sus padres, por el catecismo, por los confe- 
sores". ${ }^{20}$ De tal modo que tenemos la impresión de que Asunción, en unos cuantos años, será la exacta reproducción de su madre, descrita en una frase: "Acabó por no pensar sino en enfermedades y en milagros". ${ }^{21}$

En su afán por probar su tesis, Gálvez quizás va demasiado lejos y quizás esta observación sea errada psicológicamente: "Asunción hubiera perdonado a su marido un defecto cualquiera, hasta una aventura, pero no ese afán de hacer mil cosas, ese sentido un poco mecánico de la existencia". ${ }^{22}$ Hay en esta velada crítica al espiritu de la ciudad, un reconocimiento de los valores poéticos y espirituales de la provincia.

Esta figura femenina, no muy fuertemente trazada, de esposa común y corriente, parece solamente usada como una especie de decorado, pero de importante decorado, para que el autor pueda hacer resaltar sus otros personajes; para servir como de una especie de medida de peso en la balanza de sus ideas y hasta quizás para justificarlas.

Porque Asunción es demasiado provinciana, conservadora, estática. De Gálvez se podría decir lo que él dice de Urgel: "En su manía de explicarlo todo por el conflicto entre el pasado y el presente, por la vida estática y la vida dinámica, había empezado a derivar toda una moral del dinamismo". ${ }^{23}$

\section{CLOTA}

O el amor-imaginación.

Una importante conclusión parece brotar de esta aventura: "...y dedujo que a las mujeres no les apasionaba en realidad sino una cosa: el amor. De aquí la inferioridad de las mujeres escritoras y artistas en general; y de aquí también que sólo en literatura. descollasen realmente y cuando hablaban de amor". ${ }^{24} \mathrm{El}$ resto del libro parece probar esta aserción; no hay ni una sola mujer "fuerte". Y si recorremos la galería de mujeres de Gálvez, nos será difícil encontrar una, como en otros autores, como en otras literaturas hasta hace muy pocos lustros. ¿Quiere esto decir que la existencia de una mujer decididamente interesada en su trabajo, entusiasmada con 
él, prefiriéndolo si tuviera que elegir entre él y un hogar, es solamente un fenómeno de los últimos diez años, más o menos? ¿ O que mujeres así no existen en realidad? Pero dejemos este punto tan discutible y $\tan$ discutido.

En Clota, Gálvez pinta a una hermana de Carlos Riga: mujer de gran sensibilidad, artista, inteligente, es un alma trágica y sufriente. Una especie de personaje de novela rusa. Pero en su deseo de mostrarla como personaje trágico, exagera la nota y el resultado es el de un impaciente cansancio producido por una perenne tensión melodramática en sus cartas desgarradoras, en sus palabras torturadas, en sus ademanes sufrientes. Este personaje parece imbuído de un sentido aristotélico de la tragedia, en su constante prever el destino. $Y$ uno puede tal yez comprender a Clota, quizás sentir compasión por ella, pero no amarla.

La aventura dura poco. Un encuentro casual, poca atracción de los sentidos o del intelecto, algún interés, va desarrollándose en unas pocas entrevistas en que, debido al enorme poder imaginativo de ambos, se creen enamorados apasionadamente. Pero una entrega demasiado fácil y unos cuantos detalles materiales producen una completa desilusión en ambos. Después de lo cual él no puede contintiar fingiendo y ella, que había en realidad estado plenamente consciente de lo ilusorio de este cariño, no quiere continuar fingiendo creer en su amor (el asunto es menos complicado de lo que parece al leer esta frase).

Este tipo femenino corresponde al de los torturados, angustiados protagonistas de las novelas de esa época, de los protagonistas masculinos. Un paralelo muy semejante, pues es el resultado de la misma hipersensibilidad, de las mismas reacciones emotivas, del mismo choque contra un brutal medio ambiente, aunque sus problemas sean diferentes.

$Y$ dice el autor refiriéndose a Clota: “... era uno de los prototipos más representativos y perfectos (de la muchacha porteña moderna) pues reunía todas las características de su modalidad: la inquietud, el ansia de vivir, el horror del hastío, el anhelo del amor y la desesperanza de encontrarlo, el ensueño perenne, la inconstancia de sus sentimientos, el escepticismo de la vida y de los hombres". ${ }^{25}$ "Las que van al amor por imaginación o buscando llenar 
con algo el vacío de sus vidas y sus almas o por desesperación trágica". ${ }^{26}$

El sentido trágico de la vida. Clota era una de esas personas "... que llevan la tragedia en su interior, que nacen para sufrir y hacer sufrir a los demás, que viven silenciosamente, ocultamente, un perpetuo drama que las devora, que a los íntimos hechos los tornan trascendentales y que en el fondo no aman la vida aunque ellas crean amarla". 27

\section{AURELIA}

O el amor-pasión. O descripción de un capítulo en la vida amorosa de Urgel, en que se ponen más en evidencia tanto el estilo de Gálvez como sus grandes defectos como pensador y como autor.

Pero véamos en primer lugar cómo describe el autor lo que le gusta llamar amor-pasión. Al salir de las Cámaras después de un triunfo oratorio, Urgel se encuentra con unos ojos de mujer. Desde ese momento vive intrigado por ellos. Cuando, algunos meses después, encuentra en la puerta de una tienda a la dueña de esos ojos "su mirada, su alma, su ser entero fué hacia ellos con la fuerza violenta de su ansiedad de amor". ${ }^{28} \mathrm{Y}$ en este momento empieza entre ellos un intercambio de miradas poderosamente sensual y descrito con un lujo oriental de detalles. Miradas con las que se acarician, con las que conversan, con las que se hablan de amor. Tan elocuentemente, que la segunda vez que se hablan ella se entrega a él. $\mathrm{Y}$ desde entonces empieza un crescendo en el amor de ella: un crescendo angustioso, pasional, sensual, lleno de ternura. $Y$ por el contrario, desde el momento de la entrega, el amor de él o más bien la atracción que sintió, el interés pasajero, empiezan a disminuir rápidamente. El cansancio y el hastío empiezan a torturarle. Algún tiempo después se separan. Para desesperación de Aurora e infinito desahogo de Urgel.

Pero en este capítulo está concentrado todo el romanticismo de Gálvez. Que es mucho. Se encuentra en la descripción de los sentimientos, en el lenguaje, en la manera de ver a la humanidad. Es éste un trozo de literatura lleno de lágrimas, ternuras, invocaciones 
a la Fortuna, reflexiones tristes, desilusiones, sombra; todo cubierto por un velo de sentimentalismo, con mucho de melodramático $\mathrm{y}$ no poco de vulgaridad.

La pintura exagerada de Aurelia, en la que todo es llevado a los extremos más violentos, resulta una golosina demasiado dulce. $\mathrm{Y}$ nos acordamos de las palabras de $\mathrm{A}$. Torres Rioseco refiriéndose a este mismo autor: "De lo cual (de su número extraordinario de argumentos) resultá que sus hombres y mujeres se tiñen inmediatamente de un color novelesco y terminan por convertirse en caricaturas". ${ }^{29}$

$Y$ es que, aunque no podemos probarlo, a pesar de sus protestas de objetividad ${ }^{1}$ este capítulo es completamente subjetivo. El está "sintiendo" a sus personajes cuando trata de racionalizarlos. Se crea conflictos entre la pintura que quiere hacer de un espíritu de mujer y la compasión y simpatía que siente por este tipo de mujeres que, aunque exagerado en sumo grado, se adivina que es al que se siente más atraído instintivamente.

He dicho que es uno de los capítulos más débiles. Porque en él se encuentran las pruebas de la poca universalidad de este escritor. Su modo de ver las cosas está pasado de moda; su lenguaje, también. Hay demasiados lloriqueos, demasiadas descripciones eróticas y muy poca profundidad, en todo. él. Todo nos suena en. los oídos como una especie de "Canto a Teresa", sólo que mucho, mucho más inferior. Y la superficialidad, no de los problemas sino de la manera de enfocarlos, presentarlos y describirlos, salta a la vista.

\section{MARTA}

O el amor-piedad. "Genialidad del corazón como to hay del intelecto o de la voluntad". ${ }^{30}$ Verdadera genialidad porque Marta es el sentimiento humanitario encarnado en mujer. ¿Y hay algo más femenino que el humanitarismo? Femenino, en el mejor sentido de la palabra, en lo que tiene de espiritual, de elevado, de noble.

$\mathrm{El}$ amor maternal. Ese amor que es más fuerte que el más fuerte amor. Porque significa generosidad, entrega, ternura, piedad. Feliz el hombre que tiene una mujer así, en su vida. Y esta clase de 
sentimiento es el que Gálvez ha intentado pintar. Sin conseguirlo. Por su conocido defecto: la exageración.

Marta es una muchacha que se entrega o más bien que se somete a las caricias más íntimas y más apasionadas, por parte de Urgel, a pesar de no sentir placer alguno en ello y más bien disgusto y sufrimiento, solamente por la inmensa compasión que siente al oír las quejas de su amigo, a quien sus negativas desesperan. De inteligencia normal, sin poseer gran cultura o grandes atractivos, es éste uno de los personajes más reales de Gálvez. Su catolicismo, su ingenuidad, su bondad nos hacen pensar en esas borrosas personalidades que todos conocemos; borrosas debido precisamente a su mucha virtud.

Como Gálvez está interesado principalmente (interesado es una palabra muy débil para expresarlo: obsesionado, más bien) por la forma en que reaccionan sus personajes ante el amor, no ha podido presentar con suficiente fuerza el carácter de una mujer muy interesante $y$, a mi modo de ver, representativa del elemento femenino en Hispanoamérica y mucho más convincènte.

Marta es el instinto maternal hecho persona (¿ el sentimiento más elevado o el más primitivo, en la mujer?). Aunque está enamorada de Urgel, sus caricias no le interesan; su amor carece de sensualidad, está todo formado de una mezcla de ternura, compasión, simpatía, amistad. De esta clase son, probablemente, los sentimientos que inspiran a las Hermanas de la Caridad, a las enfermeras y a toda la enorme legión de mujeres constituída por esas esposas y madres abnegadas, resignadas, que existen solamente para sus esposos $y$ sus hijos, sin poder concebir una existencia diferente.

Entre todos los tipos de mujer que Gálvez nos ha presentado, ¿no es éste el más general? ¿No es ésta, típicamente, "la Mujer"? Por supuesto, sería ridículo seguir con este tema que tantas discusiones ha engendrado y tan pocos acuerdos. La única razón por la que mencionamos este problema es que nos parece que Gálvez no lo ha visto en esa forma o, por lo menos, no lo ha presentado en esta forma. El parece considerar a esta mujer como excepcional, considerar a su virtud como un mirlo blanco, sorprenderse ante su bondad. $Y$ es que, y aquí tenemos una de las fallas del libro, es absurdo mirar algo o a alquien solamente desde un ángulo: el mismo ángulo o el mismo punto de vista. $\mathrm{Y}$ el amante no ha sido el es- 
poso, y el esposo no ha sido el padre, y el padre no ha sido el hijo. Y Gálvez no ha mostrado el alma de mujer; ha mostrado las reacciones de algunas mujeres, al verse confrontadas con cierto problema.

\section{ELSA}

O el amor intelectual. ¿Encontraba de mal gusto, quizá cursi, 0 en todo caso teatral o insincero, el sentimentalismo? ${ }^{31}$ Para Elsa, el amor debía ser algo espiritual e inmaterial, la compenetración y profunda comprensión de dos almas. El encuentro de dos sensibilidades $y$ de dos espíritus. Ella no comprendía el amor físico. ${ }^{3 t}$

He aquí descrito el tipo de persona completamente opuesto al descrito en el capítulo anterior y por consiguiente mucho más raro de encontrar. Es Elsa mujer de sensibilidad exquisita, y de un exquisito refinamiento de espíritu (interesante también y discutible la distinción que establece el autor entre alma y espíritu). Mujer de gran sutileza, de espíritu aristocrático, de gran fuerza intelectual y muy poco poder emocional, siente una gran repulsión por el amor sensual; repulsión a la que parece haber contribuído el hecho de estar casada con un hombre que representa la antítesis de su personalidad.

Elsa se enamora (intelectualmente) de Urgel; pero a la primera tentativa de éste de besarla en los labios, su desilusión es infinita y la atracción que había sentido un año hacia él, desaparece por completo. $\mathrm{Y}$ eso es todo.

Pero es curioso que al describir a esta mujer se insiste en lo poco común que es esta clase de personalidad, especialmente entre las argentinas. Se afirma que esta clase de mujeres se podría encontrar mucho más frecuentemente entre las altas clases sociales europeas, ya que, suponemos, debido a que la Argentina carece de esas exquisiteces de antigua aristocracia en decadencia, el ambiente no es favorable a la formación de esta especie de raras perlas.

Interesante figura es ésta, en la que Gálvez ha tratado de expresar toda la delicadeza de su espíritu y de su lenguaje. En ella hay esa angustia de enorme soledad espiritual de casi todos sus personajes (y la de tantos personajes de novelas hispanoamericanas 
de ese tiempo) ${ }^{32}$ péro en ella esa desesperación es aún más real o para ponerlo en mejor forma, la sentimos aún más que en Lita o en Clota o en Aurelia porque el personaje es tan sensitivo, tan delicado, tan fácilmente herido. $Y$ también porque, debido a su mayor inteligencia, su poder de sufrimiento es mayor -tesis en la que no podemos detenernos ahora: volúmenes se podría escribir sobre ellao sea que por su inteligencia y sensibilidad la ponemos al mismo nivel que a Carlos Riga, mientras que elevamos su dolor a la quinta potencia, al pensar que ella no tiene las posibilidades de acción que Riga, por el hecho de ser hombre, tiene. $Y$ las pocas oportunidades de actuar aumentan lo reconcentrado del dolor.

Hay una poderosa lógica en los caracteres humanos y en los acontecimientos que es forzoso respetar, dice León Daudet. $\mathrm{Y}$ he aquí que Gálvez no hace el necesario uso de la lógica en los acontecimientos que narra. $O$ por lo menos, sus personajes femeninos son profundamente ilógicos en todo momento. Sin que a él parezca preocuparle el hecho de que una mujer a quien él ha pintado dotada de una nobilísima serenidad y de una gran inteligencia se comporte en forma tan absurdamente emocional e histérica. Porque aunque la escena final, la del beso no dado, esté muy realmente descrita, constituye en tal medida un anti-clímax, una negación absoluta de todo lo anterior, que nos sorprende como un golpe. Pero no importa. Hemos conocido a Elsa y eso constituye una especie de compensación.

\section{LUCY}

O la voluntad de amar. Y la incapacidad de amar. Por su cerebralismo y su independencia, Lucy, la que no pudo amar, es la única a quien Urgel, que se interesó por tantísimas mujeres, ha amado y ama.

Es Lucy la verdadera mujer moderna de la obra de Gálvez. En el real sentido de modernidad: verdad, sinceridad, vitalidad, inteligencia, independencia, la hacen tan diferente de las mujeres de épocas anteriores. Pero son esas mismas cualidades las que la incapacitan para la ternura, la piedad, la compasión, el interés por los pequeños detalles de la existencia diaria. 
Lucy es joven y bella. Enteramente franca y sincera con él desde el primer momento, se le entrega cuando unas pocas semanas después cree amarle. $\mathrm{E}$ inmediatamente viene la desilusión. ¿Causada por el amor físico, por poca delicadeza de él, por remordimientos? No. Porque él ofreció casarse con ella, en vez de proponerle irse a vivir con él. Extraña paradoja que no nos sorprende si leemos la historia completa y nos adentramos en el espíritu de la heroína. Escuchémosla: "Yo quería que el hombre a quien amase fuese libre, anárquicamente libre, incapaz de pensar en eso que tú has pensado; que no se pareciese a los demás, llenos de prejuicios sociales, cobardes, respetuosos de todas las normas. Yo quería que fuese un hombre capaz de decirme: 'ahora te vienes a vivir conmigo'. Me he desilusionado. Veo con absoluta claridad que no eres mi hombre." 33

¿Mujer fuerte? Por lo menos debemos reconocer que es diferente de las demás y que trae algo nuevo, algo como un soplo de vida nueva, en el ambiente un poco hiperestésico, un poco enfermizo en que se mueve inquietamente, incesantemente este personaje - ¿fuerte? - de Gálvez, constantemente en busca del amor de una mujer.

$\mathrm{Y}$ el único amor de Urgel es rechazado. La única mujer que él ha amado no está lo suficientemente interesada en él.

Pero la nota final no es de desesperanza: "Espera siempre ... siempre... aun cuando ya no tengas motivos de esperar..." \$4

Para resumir en una frase la idea que se viene repitiendo a través del libro:

"El dinamismo físico de la hercúlea Metrópolis encontróse con el espiritual dinamismo de los hombres nuevos". ${ }^{34}$

\section{CONCLUSIONES}

He estado tratando de encontrar la respuesta a unas cuantas dudas que se me vinieron a la cabeza al empezar este trabajo. Y me parece mejor tratar de contestarlas, si hemos de llegar a alguna conclusión.

¿Es Gálvez tan objetivo como cree serlo? 
"El medio ambiente en que Gálvez hace vivir a sus personajes no es el ambiente argentino, eso es falso. Nos denigra gratuitamente" ${ }^{35}$ se nos dice, mientras que Julio Noé ${ }^{36}$ sostiene "El mérito fundamental de Gálvez consiste, precisamente, en haber tratado esos nuevos tipos con exactitud que no podría desconocérsele y en haber descrito el ambiente porteño con vigor y verdad no comunes en nuestros hombres de letras", para añadir ${ }^{36}$ "Son argentinos purísimos, conforme a las características nuevas pero viven al margen de la común vida argentina". "A menudo triunfa su romanticismo sobre su deber de escritor realista" escribe muy justamente Torres Rioseco, ${ }^{2}$ y al leer a Francisco Contreras: ${ }^{3}$ "... Nuestros novelistas de la ciudad ... sus obras son grandes cuadros, productos de la observación y documentación, encarados bajo un punto de vista más o menos sociológico. M. Gálvez que es el primer novelista de la Argentina es uno de los representantes más característicos de esa tendencia”, oímos: ¿Dónde está la verdad? Creemos que Gálvez trató sinceramente de ser objetivo, de hacer un trabajo científico; creemos también que probablemente se vanagloria de ser un espíritu nuevo, de no dejarse llevar por sus sentimientos y de ser capaz de observar fríamente el medio ambiente. Mas para hacer un trabajo así, se necesita haber nacido con cualidades especiales que Gálvez no poseía. A través de sus libros nos parece ver al hombre: entusiasmándose por sus personajes, sintiendo simpatía o antipatía por ellos, repitiendo las mismas teorías en boca de diversos caracteres, insinuando las mismas convicciones. No. Gálvez trató de ser, quizás creyó ser objetivo, sin haberlo conseguido plenamente jamás. Y en cambio, muchas veces consigue efectos completamente distintos, en su afán de querer rodear a sus libros de una atmósfera de realismo. Bien nos lo dice Ramón Doll: ${ }^{16}$ "es inquisidor de minucias de importancia discutible o de ninguna importancia", y Alvaro Melián Lafinur: "Gálvez ha incurrido en un exceso de minuciosidad. Cae a menudo en lo fotográfico alejándose de lo pictórico. Su obra peca por abundancia" 37 "y extremando el realismo, en principio tan acertado, Gálvez ha incurrido en una deformación caricaturesca de muchas cosas". Y Julio Noé, en su artículo ya citado, dice: "En su celo verista, Gálvez nos dice todo lo que ha visto, aun lo insignificante. Por eso su novela, como los cuadros en que el pintor ha detallado los últimos planos como los primeros, carece de relieves." El mejor 
ejemplo es Nacha Régules que pudiendo haber sido un libro excelente consigue cansar al lector en la mitad de su lectura, con la repetición ad infinitum de los mismos sucesos, llevados a cabo en idéntica forma y siendo relatados con la misma inacabable sucesión de detalles. $Y$ éstos son los mismos detalles que nos hacen pensar que Gálvez, al querer pintar el crecimiento y desarrollo del alma de un pueblo, nos ha estado pintando su propia alma. No puede seguir el consejo de André Gide: escuchar a los personajes antes que dirigirlos; órlos hablar aun antes de conocerlos y saber que existen por lo que les oye decir. Porque en sus páginas aparece constantemente el autor, el hombre. Esto hubiera complacido a Anatole France (pues constantemente, en sus libros, nos encontramos con el hombre más que con el artista) y los juegos de pasiones, las ideas y los sentimientos están observados desde dentro. $\mathrm{Y}$ estas palabras no se dicen tratando de disminuir su valor. Torres Rioseco dice de él: "sólo la larga vida interna nos da abundancia y generosidad de expresión". ${ }^{2}$ Así pues, aunque no le creamos tan objetivo como él hubiese querido ser y notemos en su obra la fuerte influencia de sus teorías y opiniones, esto no rebajará el valor que ella tiene.

En cuanto a la lucha entre el espírtu estático y el espírtu dinámico, que se opera tanto en Gálvez como en sus novelas, parece que, por lo menos a juzgar por los libros que mencionamos y muy especialmente por La tragedia de un hombre fuerte, finalmente siempre es el espíritu dinámico el triunfante. "Víctor pensó en aquella lucha del espíritu estático y el espíritu dinámico. La moral vieja, el Pasado, se defendían, por los medios más viles, contra toda innovación. Pero era inútil. Y así como la fisonomía material del país se había transformado, así se transformaba también su fisonomía moral". ${ }^{38} \mathrm{Y}$ basta observar a sus personajes y estudiar la forma en que los describe. ¿No son Nacha, Raselda y Asunción el espíritu. estático personificado en mujer, Clota, Aurelia y Marta el espíritu de transición, Lita, Elsa y Lucy ejemplos del dinamismo en la atmósfera? ¿Y no es finalmente Lucy la triunfante, la mujer más fuerte que el hombre fuerte?

En cuanto al problema del argentinismo de Gálvez o de sus obras, pensamos que es difícil de resolver. Creemos que él trató de libertarse de la fuerte influencia europea, y como dice A. Chapman: "One of the most noteworthy tendencies in Latin-American 
Literature today is nationalism, manifesting a desire to be freed from the European modes which for so long have shaped the thought processes of this hemisphere." También citamos una vez más lo que dice el mismo autor, acerca de las ciudades americanas ${ }^{10}$ y lo que dicen Portuondo y Torres Rioseco, ${ }^{10}$ acerca de la influencia extranjera. Vemos, pues, que hay un consciente deseo de independencia en el arte $\mathrm{y}$ en la vida. Pero, y hablamos tanto en general como refiriéndonos a este caso en particular, es difícil desligarse completamente de algo que forma parte de uno mismo. Es el caso de la Argentina, país formado casi enteramente por corrientes de inmigrantes casi todos europeos; inmigrantes que van aumentando año tras año; corrientes que se van renovando año tras año. Es el caso de Gálvez, educado de acuerdo con moldes europeos, descendiente de una familia que sentía gran admiración por Europa, cuyas lecturas fueron en su mayor parte de libros escritos por autores franceses, rusos o ingleses, que viajó extensamente por Europa. ¿Vamos a creer que es posible sacudir de una nación o de un espíritu una influencia como ésta?

¿Qué clase de obra es la de Manuel Gálvez?

Tememos que, juzgándola por los libros que conocemos, se nos haga necesario señalar unos cuantos defectos que nos parece constituyen la razón por la que el enorme renombre de este escritor ha ido declinando tan rápidamente, aunque por la importancia que en un cierto período tuvo su obra, por su antiguo prestigio y por sus muchos años de trabajo, sea el patriarca de las letras argentinas.

Gálvez es un escritor desordenado, de obra muy desigual y que ha escrito quizás demasiado. A este respecto, no podemos menos que recordar las palabras de Suárez de Figueroa: "Sean los escritos hidalgos, esto es, de más calidad que cantidad, que no consiste la opinión de sabio en lo mucho sino en lo bueno", y de pensar que a esta enorme producción se le pude llamar con Bonet "40 "la plaga del repentismo". Salaverri dice que su prosa es "... suelta, un poco desigual pero siempre fluida y muy elocuente. En los intermedios líricos corre más alada, se hace musical y a veces cobra elegancia." Torres Rioseco está de acuerdo: "Narra con sencillez, minuciosa enumeración, repeticiones, casi elegancia..." dice, mientras que R. Doll le ataca, quizás un poco exageradamente ${ }^{10}$ "... Gálvez cree que hay una técnica de la novela ... . . . acaso en este pro- 
fundo error de Gálvez estriba todo el desastre de su obra de novelista..." En realidad, este enojo se debe a las acostumbradas arrogancias de Gálvez que, como buen triunfador, era (y es) un gran egotista. Pero se puede decir, sin gran temor a equivocarnos, que sin ser un artífice de la prosa y excepto en algunos pasajes en que se nota su gran impaciencia por terminar o cuando, como dice Julio Noé: ${ }^{5}$ "el estilo caprichoso, desaliñado y pintoresco de sus obras recientes responde en parte a propósito del autor; posiblemente el deseo de hacer ver con mayor intensidad las escenas que describe, y sobre todo, a caracterizar el ambiente argentino", con lo que no estamos completamente de acuerdo; su lenguaje fluye con facilidad y con elegancia y posee además, en alto grado, la capacidad de describir una emoción, una escena o una persona, en tres o cuatro frases, con lo que puede producir excelentes efectos.

Pensando en las novelas de este autor, nos vienen a la mente unas observaciones de Arnold Bennett que Ciro Alegría menciona: ${ }^{41}$ "La falta es de calidad. En efecto ¿ cuántos son los protagonistas que logran destacarse realmente? ¿Cuáles son los que tienen un trazo firme y convencen como seres vivientes?... La base de la buena novela está en la creación de caracteres y en nada más..." Pensamos en estas palabras y en el artículo de Torres Rioseco sobre Don Segundo Sombra ${ }^{11}$ y nos vemos obligados a confesar que entre la gran cantidad de caracteres que Gálvez ha empleado en sus libros, ninguno podría acercarse siquiera a la magnífica figura, calma y serena.

$Y$ esto nos trae, por su íntima relación, al principal defecto en las obras de Gálvez: su falta de universalidad. Sus novelas son libros que ya pasaron de moda, sus caracteres son retratos de personas que ya no existen. A pesar de lo mucho que él trató de estudiar seriamente la psicología de sus personajes, y véase lo convencidos que se muestran los críticos a este respecto: "El análisis psicológico se ha desarrollado en esta novela con una perspicacia y minuciosidad extraordinaria." " "Nadie tiene tanto como usted el sentido de la psicología femenina. Habla usted de la vida con una sencillez que oculta la profundidad con la cual usted la sondea." $42 \mathrm{Y}$ a pesar de haber tratado de hacer, contrariamente a lo que Fernando Alegría, quizás generalizando demasiado, ${ }^{43}$ había negado diciendo: "La empresa de analizar al hispano-americano debiera ser la materia de nues- 
tra novela psicológica. En vez de eso los novelistas llamados psicólogos se dedican a interpretar con estilo renovado tramas pasionales que agotaron ya la novela francesa y española...", sus caracteres nunca llegan a ser lo que quería A. Torres Rioseco, cuando dice en Occidental: "Verdad es que la novela ha venido evolucionando de la forma narrativa a la de presentación, o por mejor decir, de revelación. Queremos la comunicación directa con los caracteres, queremos más, llegar a ser nosotros mismos personajes integrantes de la novela." ${ }_{44}$ En realidad, Gálvez cae a menudo en el teatralismo y el melodrama o en el énfasis en la observación psicológica. Y "el análisis psicológico exagerado como la descripción minuciosa es una desproporción y el arte actual tiende a la armonía sintética".

\section{Mireya Jaimes Freyre, University of California, Berkeley.}

\section{N O T A S}

1 Gálvez, M. La tragedia de un hombre fuerte. (Buenos Aires), Bib. de Nov. Am., 1922, p. 8.

2 A propósito, véase Torres Rioseco, A. Novelistas contemporáneos de América, ed. Nascimento, Chile, 1939, pp. 250-270.

3 Contreras, Francisco. "La tragedia de un hombre fuerte", Mercure de France, reproducido en Nosotros. (Buenos Aires), núm. 44, 1923, pp. 414-416.

4 Torres Rioseco (2), p. 263, dice: "Gálvez usa un número extraordinario de argumentos y razones para convencernos de que sus personajes están actuando de acuerdo con la realidad, para convencerse a sí mismo en primer lugar y después al lector".

5 Noé, Julio. "El mal metafísico". Nosotros, núm, 21, 1916, pp. 393-400. Se muestra completamente convencido.

6 Para corroborar mis palabras, puedo citar las de Torres Rioseco (2): "Gálvez es a pesar de todo un introvertido y por lo tanto sus novelas son mejores cuanto más cerca están sus protagonistas de su yo". Y nótese que hay muy pocos protagonistas que no estén cerca de su yo, ya sean éstos femeninos o masculinos.

$7 \mathrm{Y}$ volviendo a citar el trabajo anterior, p. 262, “... a veces esta sociedad ni siquiera es la real sino que es sólo la abstracción que el novelista 
ha hecho de ella y los personajes pasan a ocupar el lugar secundario de mecanismos destinados a ilustrar las ideas del autor".

8 Rodrigues, Mario. Correio de Manha, reproducido en Nosotros, núm. 39, 1921, pp. 417-419.

9 Chapman, A. Perspectiva de la novela de la ciudad en Chile, La novela iberoamericana, 1951, pp. 193-212.

b) Portuondo, J. A. El rasgo predominante en la novela hispanoamericana, ibid., pp. 79-87.

c) Torres Rioseco, A. (2), p. 259.

10 "La maestra normal", Nosotros, núm. 21, 1916, p. 400.

11 Torres Rioseco, "Definición de Don Segundo Sombra" (La novela iberoamericana), p. 259.

12 Cejador, J. "Carta", Nosotros, 1917, p. 284.

13 Nacha Régules, ed. Pax, Buenos Aires, 1922, pp. 49 y 263.

14 ¡Cuán diferente $\mathrm{y}$ cuánto más profundo es el significado de las mismas palabras, repetidas una y otra vez en Madame Bovary!

15 Nosotros, núm. 44, 1923, pp. 283-284.

16 Doll, R. "Jornadas de agonía y la técnica de Gálvez", Nosotros, núm. 67, 1930, pp. 126-130.

17 En su estudio ya citado (10), p. 206.

18 Pillement, G. "M. G. y la novela argentina moderna", Nosotros, núm. 71, 1931, pp. 307-311.

19 Salaverri, V. A. "La tragedia de un hombre fuerte", Pegaso. (Montevideo), junio, 1922.
20 (1) p. 74.
21 (1) p. 51.
22 (1) pp. 76-77.
23 (1) p. 242.
24 (1) p. 292.
25 (1) p. 120.
26 (1) p. 121.
27 (1) p. 101. 
28 (1) D. 173.

29 (1) p. 263.

30 (1) p. 294.

31 (1) pp. 364-365.

32 Muy interesante es la explicación de A. Chapman, con referencia a esta conciencia de soledad en la Argentina, en su trabajo "Terms of spiritual isolation in E. Mallea", The Modern Language Forum, March-June, 1952.

33 (1) p. 430.

34 (1) p. 447.

35 "Hombres en soledad", Estudios de la Academia Literaria de La Plata, año 28 , t. 60 , sep., 1938.

36 (5) pp. 395-396.

37 "La maestra normal", Nosotros, núm. 17, 1915, pp. 95-100.

38 (1) p. 336.

39 "Observations on the Roto in Chilean fiction", Hispania, 1949, pp. 309. 314.

40 Bonet, C. A. "La plaga del repentismo", Palabras, 1935, "mas el ejercicio constante no se traduce en progreso".

41 "Notas sobre el personaje en la novela hispanoamericana" (9).

42 Miomandre, F. "Carta a Gálvez", Nosotros, núm. 40, 1922, pp. 122-123.

43 "Una clasificación de las novelas hispano-americanas contemporáneas", (9).

44 Torres Rioseco, A. "De la novela en América", Occidental, mayo, 1949. 
